\title{
Interference with the Expression of the N Gene Function of Phage $\lambda$ in a Mutant of Escherichia coli
}

\author{
DAVID I. FRIEDMAN, CAROL T. JOLLY, AND RICHARD J. MURAL \\ Department of Microbiology, Medical School, The University of Michigan, Ann Arbor, Michigan 48104 \\ Accepled October 12, 1972
}

\begin{abstract}
An Escherichia coli mutant nus, which inhibits the growth of $\lambda$ by inhibiting the expression of the $\lambda \mathrm{N}$ gene product, has been further characterized. The $N$ protein regulates phage development by stimulating transcription of the $\lambda$ genome in three ways: dircetly, by stimulating transcription initiating at the two promoters, $P_{K}$ and $P_{L}$ and indirectly by stimulating the synthesis of $Q$ protein, which in turn activates transcription of late functions. We report in this study that all three types of $\lambda$ transcription are affected by the nus mutation. However, the inhibitory effect of nus on N stimulation of transcription initiating at $P_{R}$ is shown to be qualitatively different from its effect on $\mathrm{N}$ stimulation of the synthesis of $\mathrm{Q}$ product.

Evidence is also presented showing that some $\mathrm{N}$ function is expressed by $\lambda$ in the nus mutant, but that the level of expression of $\mathrm{N}$ function is reduced.
\end{abstract}

\section{INTRODUCTION}

The isolation of an Escherichia coli mutant which inhibits the growth of phage $\lambda$ was reported in a previous study (Friedman, 1971). This mutant was isolated using a selection procedure designed to yield host mutants which interfere with the $\mathrm{N}$ gene function of phage $\lambda$. Preliminary studies supported the conclusion that in this mutant the expression of $\mathrm{N}$ function by $\lambda$ was reduced or "undersupplied." The mutation was called $n u s$ for $N$ undersupplied.

Two other $E$. coli mutants which affect the expression of $\mathrm{N}$ funclion have been reported. Both of these mutations map near the gene coding for rifamycin resistance $\left(\right.$ rif $\left.{ }^{\mathbf{R}}\right)$, minute 77 on the $E$. coli chromosome (Pironio and Ghysen, 1970; Georgopoulos, 1971). Baron and co-workers (1970) have shown that a Salmonella typhosa-Escherichia coli hybrid bacterium, which carries sufficicnt $E$. coli genetic material to permit $\lambda$ adsorption, limits $\lambda$ growth by inhibiting $\mathrm{N}$ function. The $\mathrm{N}$ gene product can function in the hybrid bacterium, if an additional small region of the $E$. coli chromosome is introduced into the hybrid bacterium (Baron et al., 1972). This region lies somewhere between minutes 66 and 72. The nus mutation also has been shown to map in this same region and to be unlinked to the rif ${ }^{\mathrm{R}}$ locus by $\mathrm{P} 1$ transduction (Fricdman, manuscript in preparation). Moreover, these studies show that in a bacterium diploid for the nus region, the Nus ${ }^{+}$phenotype is dominant to the Nus phenotype.

The $\mathrm{N}$ function of phage $\lambda$, which is expressed early after infection or induction, subsequently regulates the expression of other phage functions by stimulating transcription of the $\lambda$ genome (reviewed by Echols, 1971). The transcription of three regions of the $\lambda$ genome is stimulated in the following way: transcription of the regions coding for "early" phage functions initiating from $\mathrm{P}_{\mathrm{R}}$ (the $c \mathrm{II}-\mathrm{O}-\mathrm{P}$ operon) and $\mathrm{P}_{\mathrm{L}}$ (the $\mathrm{N}$-cIII-int operon) (see Fig. 1) is directly stimulated by $\mathrm{N}$ product. Transcription of a third region, coding for "late" phage functions is stimulated by $\mathrm{Q}$ product, a function whose expression is under $\mathrm{N}$ control.

Vegetative growth of phage $\lambda$ requires only the expression of functions under $P_{\mathbf{R}}$ 


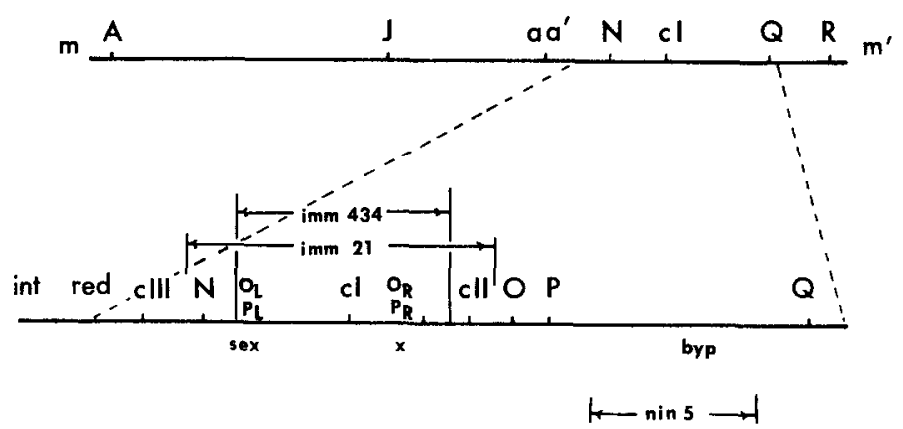

FIG. 1. Genetic map of $\lambda$ with the early region expanded.

and $Q$ control (Echols, 1971). Functions under $\mathrm{P}_{\mathrm{L}}$ control distal to $\mathrm{N}$ are involved in lysogeny and recombination and are not essential for normal phage growth. This accounts for the fact that phage carrying mutations which allow $\mathrm{N}$-independent expression of both the $c$ II-O-P operon and $\mathrm{Q}$ product permit phage growth.

Two types of $\lambda$ mutants which grow in the absence of $\mathrm{N}$ product ( $\mathrm{N}$-independent) have been isolated. The first type, $\lambda \mathrm{N}^{-} c 17 b y p$ (Butler and Echols, 1970; Hopkins, 1970), as expected from the above considerations, carries two mutations; $c 17$ (mapping in the $y$ region) which frees transcription of the cII-O-P operon from $\mathrm{N}$ control, and byp (mapping in the $\mathrm{P}-\mathrm{Q}$ region) which permits $\mathrm{Q}$ synthesis in the absence of $\mathrm{N}$ product. A second type, $\lambda$ nin (Court and Sato, 1969), is genetically altered in only one region. It carries a $5 \%$ deletion in the $\mathrm{P}-\mathrm{Q}$ region (Fiandt et al., 1971). Since the functions coded for in the cII-O-P operon are expressed, albeit at a lower level, in the absence of $\mathrm{N}$ product (Ogawa and Tomizawa, 1968; Signer, 1969; Lieb, 1970), the nin deletion must augment the normal low levels of $\mathrm{N}$-independent transcription initiating at $P_{R}$ (Court, 1970).

Bacterial mutants in which $\mathrm{N}$ product is "undersupplicd," were obtained by screening for bacteria which had the ability to plate the $\mathrm{N}$-independent phage $\lambda \mathrm{N}^{-}$c17byp under conditions where an $\mathrm{N}$-dependent phage would not plate; nus-1 was characterized as such a mutant. Although the nus-1 mutant (K-95) showed the Nus phenotype at $42^{\circ}$, it appeared to be $\mathrm{Nus}^{+}$at $34^{\circ}$. We assumed that the nus mutation resulted in the synthesis of a temperaturesensitive product (Friedman, 1971).

If, in fact, the nus mutation interfered with the expression of $\mathrm{N}$ function, we would expect that each component of $\lambda$ growth regulated by $\mathrm{N}$ product would be affected by the nus mutation. That is, for vegetative growth of $\lambda$ to occur in the bacterial mutant both $c 17$ as well as the byp mutations would be necessary. However, this was not the case. Whereas at $42^{\circ}$ the $c 17$ mutation alone was not sufficient to allow $\lambda$ to plate on K-95, the byp mutation alone was sufficient to allow $\lambda$ to plate on this host (Friednuan, 1971). This result suggested that the nus mutation might affect only one of the areas under $\mathrm{N}$ regulation, $\mathrm{N}$ stimulated turn-on of $\mathrm{Q}$ product. However, in this paper we present evidence showing that the nus mutation does, in fact, affect all three components of $\mathrm{N}$ activity.

\section{MATERIAIS AND METHODS}

Bacterial strains. The nus mutant (Friedman, 1971) was selected without mutagenesis using a $\lambda$ lysogen of $\mathrm{K}-37$ (strain 28 of Meselson's). K-37 (strain 28 of Meselson) is a str ${ }^{\mathbf{R}}$ derjvative of W3102 (Lederberg, 1960). In the experiments reported in this paper the nus mutant used is K-95, a derivative of Nus-1 which was cured of the $\lambda$ prophage. C600 (Appleyard, 1954) is a strain permissive for growth of phage carrying amber mutations.

Phage stocks. Obtained from M. Gottesman, $\lambda c \mathrm{I} 857, \lambda c \mathrm{I} 857 \operatorname{sex} 1, \lambda c \mathrm{I} 60, \mathrm{P} 2$, and P2vir; from M. Yarmolinsky, גimm $434 c \mathrm{Its}$; from I. Herskowitz, $\lambda c$ I857susN7N53. A series of phage were constructed in this labo- 
ratory: $\lambda c \mathrm{I} 857 b y p$ and $\lambda c \mathrm{I} 857$ sus $\mathrm{N} 7 \mathrm{~N} 53 b y p$ using a $\lambda s u s$ N7N53c17byp supplied by $\mathrm{H}$. Echols; $\lambda c 160$ nin using a $\lambda$ biolonins supplied by F. Blattner.

Lysogenization. $\lambda$ lysogens were constructed according to the method of Gottesman and Yarmolinsky (1968). P2 lysogens were obtained by plating $\mathrm{P} 2$ phage on a lawn of the bacteria which was to be lysogenized. Bacteria were picked from the center of the plaque and purified by streaking on a tryptone plate. Single colonies were tested for lysogeny by determining whether they would grow $\mathrm{P} 2$ vir but not $\mathrm{P} 2$.

Exonuclease determination. $\lambda$ exonuclease was assayed using Pero's (1970) modification of Radding's method (1966). However, cells were resuspended in $0.01 M$ Tris, $\mathrm{pH}$ 7.1 , instead of a glycylglycine buffer. Protein content of lysates was measured using the method of Lowry et al. (1951). One unit of activity is defined as that amount of enzyme solubilizing 10 nmoles of nucleotide in $30 \mathrm{~min}$ at $37^{\circ}$.

Media. Adsorption broth: $1 \%$ tryptone, $0.5 \% \mathrm{NaCl}, 1.0 \mu \mathrm{g} / \mathrm{ml}$ thiamine hydrochloride, $10^{-2} M \mathrm{MgSO}_{4}$ and $0.2 \%$ maltose. Tryptone agar: $1 \%$ tryptone, $0.25 \% \mathrm{NaCl}$, $1.0 \mu \mathrm{g} / \mathrm{ml}$ thiamine hydrochloride, and $1.1 \%$ agar. Tryptone top agar: $1 \%$ tryptone, $0.5 \% \mathrm{NaCl}$, and $0.7 \%$ agar.

\section{EXPERIMENTAL}

\section{Effect of the nus Mutation on $N$ Stimulation of $Q$ Expression}

The synthesis of late $\lambda$ gene products is stimulated by the $\mathrm{Q}$ gene product, the expression of $Q$, in turn, is regulated by $N$ product. In the absence of $N$ protein, $Q$ function is not expressed (reviewed by Echols, 1971). The most obvious effect of the nus mutation on $\lambda$ development is its effect on the expression of $\mathrm{Q}$ gene product. This is demonstrated by experiments showing that the restriction of $\lambda$ growth imposed by the nus mutation is overcome if the phage carries either of two mutations, nin or byp, mapping in the $\mathrm{P}-\mathrm{Q}$ region. These mutations permit $\lambda$ to express $Q$ function in the absence of $\mathrm{N}$ product.

Single-step growth experiments at $42^{\circ}$ show that although the final bursts of $\lambda$ nin and $\lambda$ byp produced in the nus mutant, K-95, are similar, the development of the two phages in the nus bacterium are quite different. A comparison of Figs. 2 and 3 shows that whereas the onset of viable phage production, at $42^{\circ}$, of $\lambda$ in is nearly the same in the nus and $n u s^{+}$bacteria, the onset of phage production of $\lambda b y p$ is delayed by over $20 \mathrm{~min}$ in the nus bacterium.

The effect of the two mutations, nin and byp, on $\lambda$ physiology are clearly quite different (reviewed by Echols, 1971). This is evident from the fact that while the nin

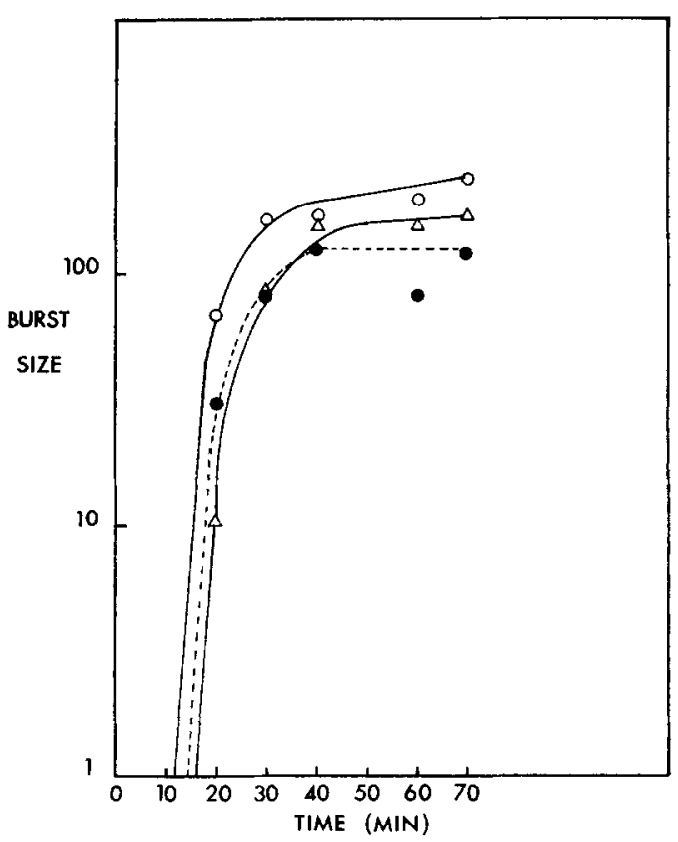

FIG. 2. Burst of $\lambda$ nin in nus at $42^{\circ}$. Bacterial strains, nus (K-95) and nus ${ }^{+}(\mathbf{K}-37)$, were grown in adsorption broth and diluted to a final concentration of $10^{8} / \mathrm{ml}$. The bacteria were infected with either $\lambda c \mathrm{I} 60$ or $\lambda$ nins at a multiplicity of infection (m.o.i.) of 0.1. Adsorption was effected by incubating the infected cell at $42^{\circ}$. Cells were then diluted into adsorption broth prewarmed at $42^{\circ}$. One-milliliter aliquots were removed at the indicated times, and a few drops of chloroform were added. The infected cells were incubated at $40^{\circ}$ for $30 \mathrm{~min}$. The lysed cultures were plated using top agar on tryptone plates. Plates were incubated at $40^{\circ}$ overnight. Burst size was computed as phage released per infected bacterium. $\bigcirc-O, \mathbf{K}-37$ infected with $\lambda c \mathrm{I} 60 ;---\mathrm{K}-37$ infected with $\lambda n i n ; \triangle-\triangle, K-95$ infeeted with $\lambda$ nin. 


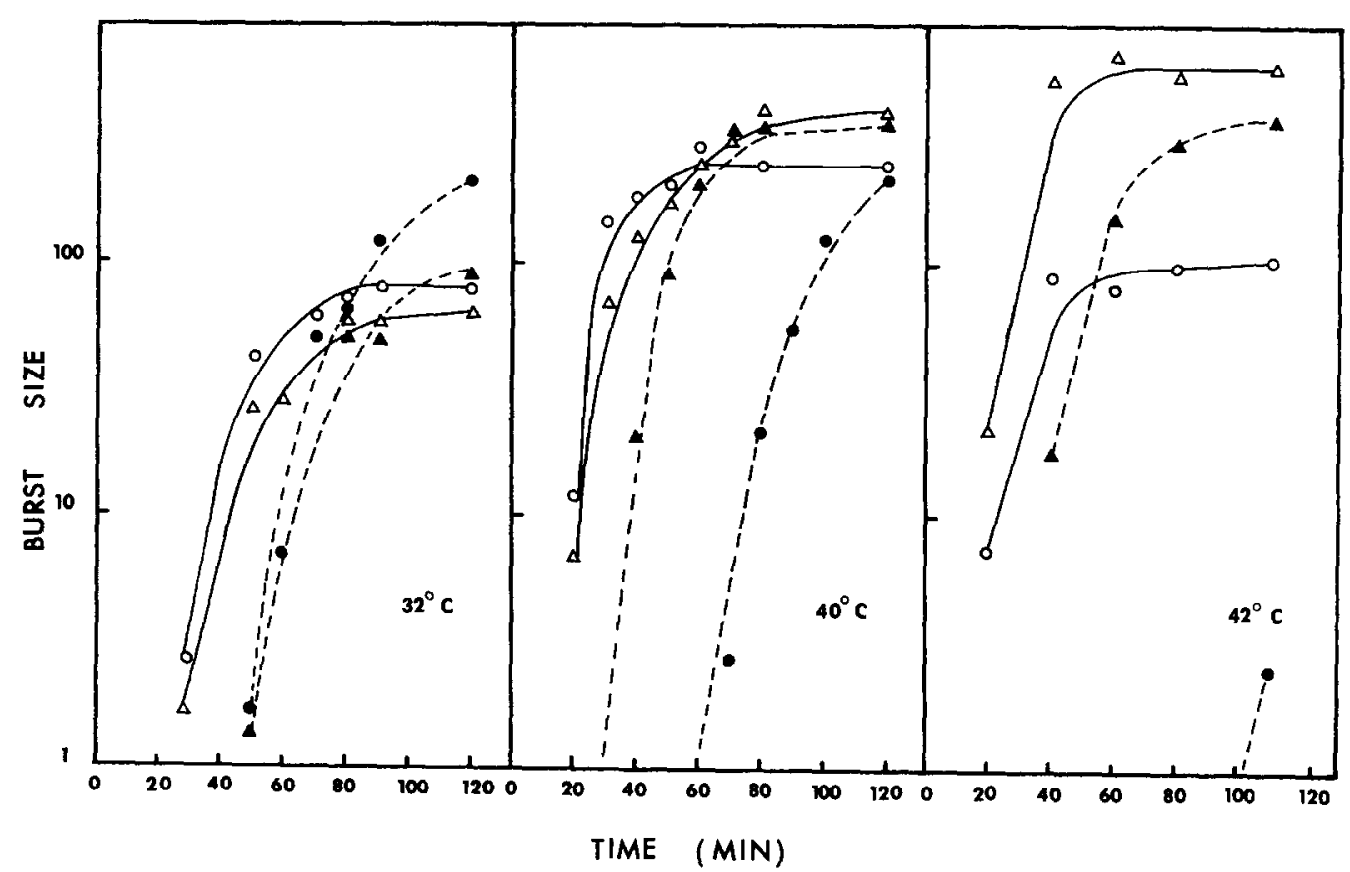

FIG. 3. Burst of $\lambda b y p$ in nus at various temperatures. The methods of phage growth and determination of burst time were the same as outlined for Fig. 2. The temperature at which each experiment was run is recorded in the lower right-hand corner of each panel. O- $\mathrm{O}, \mathrm{K}-37$ infected with $\lambda c \mathrm{I} 60 ; \mathbf{O}-\cdots, \mathrm{K}-95$ infected with $\lambda c \mathrm{I} 60 ; \Delta-\triangle, \mathrm{K}-37$ infected with $\lambda c \mathrm{I} 857$ byp; $\mathbf{\Delta} \cdots-\mathbf{\Lambda}, \mathrm{K}-95$ infected with $\lambda c 1857 b y p$

mutation is sufficient to permit $\mathrm{N}$-independent growth, the byp mutation alone does not permit $\mathrm{N}$-independent growth of $\lambda$. In order to plaque, a $\lambda \mathrm{N}^{-}$phage requires, in addition to byp, a second mutation, such as $c 17$, which frees the $c$ II-O-P operon from $\mathrm{N}$ control. The degree of $\mathrm{N}$-independence of a $\lambda$ mutant, therefore, correlates with its growth characteristics in the nus bacterium. It is not clear from these experiments why the appearance of $\lambda b y p$, in contrast to the appearance of $\lambda \mathrm{nin}$, is delayed in $\mathrm{K}-95$. Since $\mathrm{N}$ function acts in two ways to stimulate vegetative growth, this delay could either reflect (1) an interference with $\mathrm{N}$-stimulated transcription from $\mathrm{P}_{\mathrm{R}}$ or (2) an inadequate expression of $\mathrm{Q}$. In either case $\lambda$ nin must overcome the block. What is clear from these experiments is that the nus mutation inhibits the expression of $\mathrm{Q}$ function. Evidence consistent with the idea that the delay in the appearance of $\lambda b y p$ in $\mathrm{K}-95$ is due to an inhibition of $\mathrm{N}$-stimulated expression of the $c$ II-O-P operon will be presented in the next section.
Effect of the nus Mutation on $N$ Stimulation of the Expression of the cII-O-P Operon

The $\mathrm{N}$ protein stimulates transcription of the $c$ II-O-P operon which initiates at $P_{R}$ (reviewed by Echols, 1971). We have studied the effect of the nus mutation on exprcssion of this operon by measuring the level of $\mathrm{O}$ and $\mathrm{P}$ gene product. The $\mathrm{O}$ and $\mathrm{P}$ genes code for replication functions (reviewed by Kaiser, 1971). The expression of these two functions by a $\lambda$ prophage is sufficient to result in the death of the cell it lysogenizes (Pereira da Silva, et al., 1968). The induced $\lambda$ prophage expresses an additional function lethal to the host which maps in the N-cIIIint operon and is directly under $\mathrm{N}$ control (Herskowitz, personal communication). The expression of this lethal function can be eliminated by a number of different phage mutations. One of these mutations is the sex mutation (Gottesman and Weisberg, 1971), which is located in the region of $P_{L}$ (Blattner et al., 1972) and results in a lowering of the transcription initiated at $\mathrm{P}_{\mathbf{L}}$ 
(Roberts, 1969). A $\lambda$ sex phage does express sufficient $\mathrm{N}$ function to permit vegetative growth. Induction of a $\lambda$ sex prophage is lethal to the host and this lethality then must be due to the expression of $\mathrm{O}$ and $\mathrm{P}$ function. That this is the case is indicated by the fact that induction of lysogens carrying either a $\lambda \operatorname{sex} O^{-}$or $\lambda \operatorname{sex} P^{-}$prophage is not lethal (Gottesman, personal communication).

Thus, by measuring the loss of viable bacteria following the induction of a $\lambda$ sex prophage it is possible to determine the level of expression of $\lambda$ replication functions $O$ and $P$. This, in turn, should give an estimate of the level of expression of the $c$ II-O-P operon. Induction of a $\lambda c$ I 857 sex 1 prophage is lethal both to the nus mutant as well as the nus parent. But, significantly, when the kinetics of lethality are studied (Fig. 4), there is a 20 -min delay in the killing by the $\lambda$ sex prophage in the nus mutant as compared to the nus $^{+}$parent. This reflects a 20 -min delay in the expression

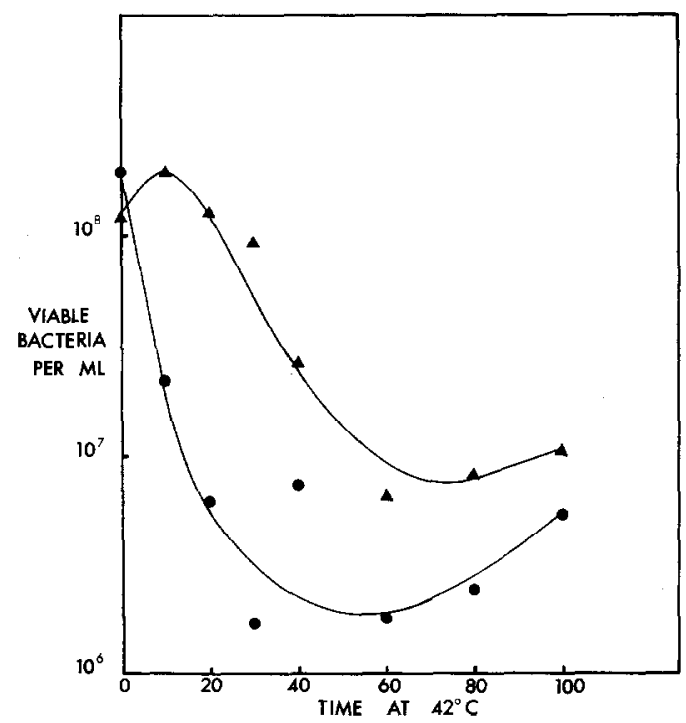

Frg. 4. Lethal effect of induced $\lambda$ sex prophage on nus and nus ${ }^{+}$bacteria. Lysogens, carrying $\lambda c$ I857sex 1 prophage, were grown to a concentration of $\sim 10^{8} / \mathrm{ml}$ at $34^{\circ}$. Cultures were shifted to $42^{\circ}$, and aliquots were removed at the indicated times and immediately plated for viable cells on tryptone agar plates. Plates were incubated at $34^{\circ}$. $\lambda c \mathrm{I} 857$ sex 1 . of the lethal functions, $\mathrm{O}$ and $\mathrm{P}$. Unreported studies by Friedman and Yarmolinsky, using a $\lambda c$ I857susN7N53 prophage, have shown that in the absence of the $\mathrm{N}$ function there is a 30 - to 35-min delay in the occurrence of prophage induced killing. Therefore, we conclude that the $20-\mathrm{min}$ delay in the onset of killing seen in the case of the $\lambda$ sex lysogen of $\mathrm{K}-95$ reflects a 20 -min delay in the N-stimulated expression of the cII-O-P operon. It is interesting to note that this delay is similar to the delay in the appearance of $\lambda$ byp following its infection of K-95 at $42^{\circ}$.

Additional experiments demonstrated that, the delay in the appearance of viable phage following infection of K-95 with $\lambda b y p$ was relatively constant over temperatures ranging from $32^{\circ}$ to $42^{\circ}$. As shown in Fig. 3 , the appearance of $\lambda b y p$ following infection of the nus mutant always lagged about $20 \mathrm{~min}$ behind its appearance following infection of the $n u s^{+}$strain. A similar delay was observed using a byp ${ }^{+}$phage, $\lambda c \mathrm{I} 60$ (Fig. $3 \mathrm{~A}$ ). However, this effect was only observed at temperatures at which the phage can plate on K-95. Comparison of the growth of $\lambda c \mathrm{I} 60$ in the nus and $n u s^{+}$hosts shows that the burst of phage decreases and the delay in appearance of phage increases as the temperature of incubation increases (Fig. 3).

The inhibition of $\lambda$ growth related to increases in temperature we ascribe to the cffect of the nus mutation on $\mathrm{Q}$ expression, since it is overcome by introducing the byp mutation. The relatively constant 20 -min delay in the appearance of phage we ascribe to the effect of the nus mutation on transcription from $P_{R}$, since this delay occurs even when the byp mutation is present.

\section{Effect of the nus Mutation on Expression of Functions in the $\mathrm{N}$-cIII-int Operon}

The operon located immediately to the left of the immunity region, the $\mathrm{N}$-cIII-int operon (see Fig. 1), includes the genetic information for the essential function $N$ as well as the information for a number of nonessential functions (Szybalski and Herskowitz, 1971). Most of the latter functions appear to be involved in lysogeny and recombination (Manly et al., 1969). Trans- 
cription of this operon initiates in the immunity region adjacent to the $\mathrm{N}$ gene at $P_{L}$. Although the $N$ gene can be transcribed in the absence of the $\mathrm{N}$ protein, the rest of the operon is not transcribed to any extent in the absence of the $\mathrm{N}$ protein (reviewed by Echols, 1971). Since the N product regulates the expression of functions in the N-cIII-int operon, we studied the effect of the nus mutation on the expression of some of the functions located in this operon.

The expression of three cistrons (red $\alpha, \delta$, or $\gamma$ ) which map in the N-cIII-int operon, inhibit the growth of $\lambda$ on a host carrying a P2 prophage, the so-called Spi phenotype (Zissler et al., 1971; Lindahl et al., 1970). A $\lambda$ mutant which is unable to express these functions will plate on such a P2 lysogen. An N-independent phage, $\lambda \mathrm{N}^{-}$nin, which cannot express $\mathrm{N}$ function and consequently does not synthesize red $\alpha, \delta$, or $\gamma$ products, can plate on a P2 lysogen (Court and Campbell, 1972). Therefore, it would be expected that a host mutant which inhibits the expression of $\mathrm{N}$, might allow an $\mathrm{N}$-independent, but $\mathrm{N}^{+}, \lambda$ to plate even if such a mutant bacterium carried a P2 prophage. We have constructed $\mathrm{P} 2$ lysogens of both the nus bacterium and its $n u s^{+}$ parent. The $\mathrm{N}^{+}$phage used in this experiment was $\lambda c$ I857byp, a phage able to plate on $\mathrm{K}-95$ even at $42^{\circ}$. As shown in Table 1 ,

TABLE 1

Effeci of nus Mutation on P2 Restriction of $\lambda$ Growth ${ }^{a}$

\begin{tabular}{lccccc}
\hline \multirow{2}{*}{$\begin{array}{c}\text { Temp } \\
\left({ }^{\circ} \mathrm{C}\right)\end{array}$} & Phage & \multicolumn{4}{c}{ Bacteria } \\
\cline { 3 - 6 } & & K-37 & $\mathrm{K}-37 \cdot \mathrm{P} 2$ & $\mathrm{~K}-95$ & $\mathrm{~K}-95 \cdot \mathrm{P} 2$ \\
32 & $\lambda c$ I857byp & + & - & + & + \\
43 & & + & - & + & + \\
32 & $\lambda$ bio10nin5 & + & + & + & + \\
43 & & + & + & + & + \\
\hline
\end{tabular}

a The nus and nus ${ }^{+}$bacteria carrying $\mathbf{P} 2$ pro. phage were grown overnight in absorption broth. Lawns of each lysogen were poured onto tryptone plates using top agar. The top agar was allowed to harden. Plates were divided in half, and a fine wire loop was used to streak a large amount of either $\lambda c 1857$ byp or $\lambda$ bio10 nin on the seeded lawn. Plates were incubated at either $32^{\circ}$ or $43^{\circ}$. If obvious phage growth was observed it was recorded as + ; if no phage growth oceurred it was recorded as - . the control phage, $\lambda$ biolonin, which is deleted for the N-cIII-int operon and is nin grows on P2 lysogens of both the nus and nus ${ }^{+}$bacterium. The $\mathrm{N}^{+}$phage $\lambda c \mathrm{I} 857 b y p$ which carries the $\mathrm{N}$-cIII-int region is also able to plate on the K-95 (P2) lysogen. However, this phage is unable to plate on the P2 lysogen of the parental nus strain. This experiment suggests that, in the nus mutant, $\lambda$ is unable to express at least three of the functions coded for in the N-cIII-int operon.

The $\lambda$ red $\alpha$ gene codes for the phage exonuclease (Shulman et al., 1970; Signer, 1971) an enzymatic activity which can easily be measured. In order to get some quantitative measure of the expression of functions lying in the $\mathrm{N}$-cIII-int operon, we have measured the levels of exonuclease synthesized following induction of a $\lambda$ prophage in both the nus mutant and its $n u s^{+}$parent. The $\lambda$ prophage carried the temperature-sensitive repressor mutation cI857, which permits prophage induction by shifting the lysogen to temperatures above $39^{\circ}$ (Sussman and Jacob, 1962). The level of cxonuclease product in the nus mutant at $42^{\circ}$ was determined using lysogens carrying $\lambda c \mathrm{I} 857$ prophage. As shown in Fig. 5, induction of $\lambda c$ I857 in the $n u s^{+}$bacterium results in the synthesis of $\lambda$ exonuclease, but induction of the same phage in the nus basterium does not result in the synthesis of $\lambda$ exonuclease. No $\lambda$ exonuclease was observed in the latter case even when assayed in extracts prepared $60 \mathrm{~min}$ after induction.

It can therefore be concluded that the nus mutation acts to inhibit expression of the $\mathrm{N}$-cIII-int operon. Since the $\mathrm{N}$ gene also lies within this operon, it is important to determine whether the $\mathrm{N}$ gene is expressed to any extent in the nus mutant.

\section{Expression of the $N$ Gene Product}

Expcriments with $\lambda$ and $\lambda b y p$ show that the $\mathrm{N}$ function is expressed in the nu.s mutant. Both these phages require $\mathrm{N}$ product for growth, and each plates on K-95 at $34^{\circ}$, with $\lambda b y p$ plating on K-95 even at high temperatures. Further, neither $\lambda c$ I8.57sus N7N53 nor $\lambda c$ I857susN7N53byp plates on K-95 at any temperature -demonstrating that $N$ product is required for $\lambda$ growth in 


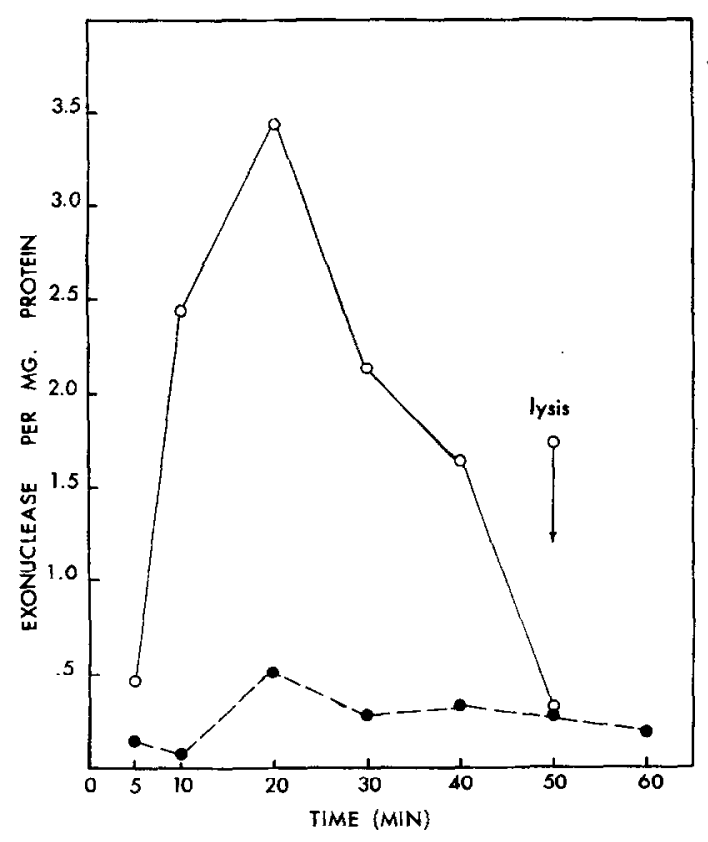

Frg. 5. Synthesis of $\lambda$ exonuclease in the nus bacterium at $42^{\circ} . \mathrm{Nus}^{+}(\mathrm{K}-37)$ and nus (K-95) lysogens each carrying a $\lambda c I 857$ prophage were grown in adsorption broth to a concentration of $\sim 10^{8} / \mathrm{ml}$ at $34^{\circ}$. Cultures were shifted to $42^{\circ}$ and aliquots of $2 \mathrm{ml}$ were removed at the indicated times, immediately cooled in an alcohol ice bath, sedimented by centrifugation, resuspended in $0.01 M$ Tris, $\mathrm{pH}$ 7.1, sonicated, cleared of debris by centrifugation, and the supernatants were assayed for exonuclease activity according to the method of Pero (1970). One unit of exonuclease activity solubilized 10 nmoles of ${ }^{3} \mathrm{H}$-labeled P22 DNA per milligram of protein in $30 \mathrm{~min}$ at $37^{\circ}$. The specific activity of the labeled DNA was $25,000 \mathrm{cpm} / \mathrm{nmole}$. $0-0$, $\mathrm{K}-37 \cdot \lambda c \mathrm{I} 857 ;-\cdots, \mathrm{K}-95 \cdot \lambda_{c} \mathrm{I} 857$.

$\mathrm{K}-95$. Thus, in the nus mutant, the $\mathrm{N}$ function is expressed under conditions where other functions in the $\mathrm{N}$-cIII-int operon are not expressed. The fact that $\mathrm{N}$ is expressed in the nus mutant was demonstrated in another way. A $\lambda$ mutant, $\lambda c I 857$ sus N7N53, which is unable to express $\mathrm{N}$ function when it infects a nonpermissive host does not kill that host, but does express sufficient replication functions to permit the phage to persist as a plasmid (Signer, 1969; Lieb, 1970). If an infecting $\lambda$ cannot express $N$ function in nus, we would expect it to act like the infecting $\mathrm{N}^{-}$phage. However, it does not; an infecting $\lambda$ fails to replicate as a plasmid in K-95 (Friedman, 1971). This - observation is consistent with the idea that $\lambda$ expresses $\mathrm{N}$ function in the nus bacterium.

If the nus mutation acts to lower the expression of $\mathrm{N}$ function, then we would expect that a phage which normally expresses lower levels of $\mathrm{N}$ function in the nus $^{+}$bacterium would express even lower levels in the nus mutant. $\lambda c I 857$ sex 1 appears to express reduced levels of $\mathrm{N}$ function in the $n u s^{+}$host. The sex mutation results in a reduced expression of the N-cIII-int operon (Gottesman and Weisberg, 1971). Specifically, the N-mRNA synthesized by this phage is 10-fold lower than that synthesized by the $s e x^{+}$phage (Nijkamp et al., 1970). The single-step growth experiments presented in Fig. 6 show that the growth of $\lambda c I 857 \operatorname{sex} 1$ is severely inhibited in the nus

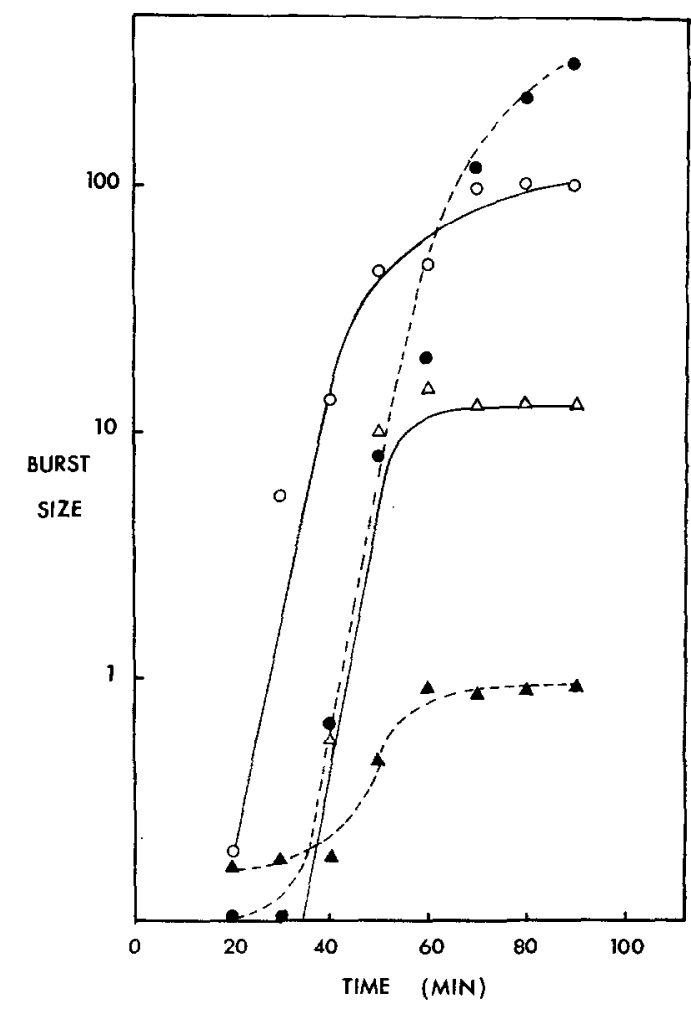

FIG. 6. Growth of $\lambda$ sex in nus. The methods of phage growth and determination of burst were the same as outlined for Fig. 2. The experiment was run at $34^{\circ}$. O-— K -37 infected with $\lambda c \mathrm{I} 60$; - K-95 infected with $\lambda c \mathrm{I} 60 ; \triangle-\triangle, \mathrm{K}-37$ infected with $\lambda c$ I857sex $1 ; \boldsymbol{\Lambda}-\cdots, \mathbf{\Lambda}, \mathbf{K}-95$ infected with $\lambda c$ I857 sex 1 . 
mutant. These experiments were run at $34^{\circ}$, a temperature at which $\lambda$ is able to grow in K-95 (see control in Fig. 6).

Studies discussed in the beginning of this section showed that $\lambda N^{-}$replicates as a plasmid; this implies that if the level of $X$ function expressed by $\lambda$ sex in the nus mutant is extremely low, then $\lambda$ sex may replicate as a plasmid in the nus host. We have exploited a unique characteristic of the $\lambda$ plasmid (Friedman and Yarmolinsky, 1972) to determine whether $\lambda$ sex grows as a plasmid. Induction of a $\lambda c$ I857 sus N7N53 prophage in $\mathrm{K}-3 \overline{7}$, a nonpermissive host, is lothal to the lysogen. However, if the lysogen is infected prior to induction with a $\lambda c I 857$ sus N7N53 phage this lethality is prevented. The lysogen now survives heat induction. This sparing cffect was shown to be due to the presence of the infecting $\lambda \mathrm{N}^{-}$ phage as a replicating plasmid.

If $\lambda$ sex is unable to express $\mathrm{N}$ function in the nus host then we would expect that it would replicate as a plasmid in that host. Further, the infecting $\lambda$ sex phage should prevent the lethality due to induction of the $\lambda$ sex prophage. Experiments presented in Table 2 demonstrate that in the nus host $\lambda$ sex acts precisely as a $\lambda \mathrm{N}$ - has been shown to act in the nus ${ }^{+}$host. An induced $\lambda$ sex

TABLE 2

Siving of Induch Lysogen by Inferting $\lambda$ MUTiN ${ }^{a}$

\begin{tabular}{|c|c|c|c|c|}
\hline \multirow[t]{2}{*}{ Iysogen } & \multicolumn{4}{|c|}{ Infecting phage } \\
\hline & $\lambda c \mathrm{I} 85 i$ & $\begin{array}{c}\lambda c \mathrm{I} 857- \\
\operatorname{sex} 1\end{array}$ & $\begin{array}{l}\lambda c \mathrm{I} 857- \\
\text { sus } \\
\text { N7N53 }\end{array}$ & None \\
\hline
\end{tabular}

\begin{tabular}{lllll}
$\mathrm{K} 37 \cdot \lambda c \mathrm{I} 857 \operatorname{sex} 1$ & - & - & - & - \\
$\mathrm{K} 95 \cdot \lambda c \mathrm{I} 857 \operatorname{sex} 1$ & - & + & + & - \\
\hline
\end{tabular}

a Lysogens were streaked onto tryptone plates and allowed to grow overnight at $34^{\circ}$. In each case, a fresh colony was picked and suspended in either a drop of each phage (titer of $5 \times 10^{8}$ ) or buffer and allowed to stand at room temperature for $20 \mathrm{~min}$. Each isolate was then streaked onto tryptone plates. The plates were incubated overnight at either $34^{\circ}$ or $40^{\circ}$. All isolates survived equally well at $34^{\circ}$. The table represents the survival pattern at $40^{\circ}$. Symbols: - , no growth; + , confluent growth. lysogen is spared both by infecting $\lambda$ sex and $\lambda \mathrm{N}^{-}$phages. Control experiments with the $n u s^{+} \cdot \lambda$ sex lysogen show that it is not spared by either infecting $\lambda$ sex or $\lambda \mathrm{N}^{-}$ phages. We conclude that $\lambda$ sex persists as a plasmid in the nus host. Thus the effects of the nus and sex mutations appear to be synergistic in their effect on $\lambda$ growth. This is consistent with our contention that the nus mutation acts by inhibiting the expression of $\mathrm{N}$ function.

It is also interesting to note that although $\lambda \operatorname{sex}$ grows in the nus ${ }^{+}$parent, the singlestep growth experiment shows that there is about a 20 -min delay in the appearance of this phage. This delay roughly corresponds to the 20 -min delay seen in the case of infection with $\lambda$ in the nus bacterium. Thus, if the expression of $\mathrm{N}$ function is interfered with in either of two ways, by a phage mutation or by a bacterial mutation, there appears to be a mild inhibitory effect on phage development manifested by a delay in the appearance of phage.

\section{DISCUSSION}

The experiments presented here extend previous studies and show that the nus mutation affects all the components of $\lambda$ growth known to be regulated by the $\mathrm{N}$ product.

The observation that the $\mathrm{N}$-independent phage Anin plates on the nus mutant under conditions where $\mathrm{N}$-dependent phage do not, suggests that the nus mutation inhibits $\lambda$ growth by interfering with the expression of $\mathrm{N}$ function. But two lines of evidence show that some $N$ function must be expressed: (1) A phage which is only partially $\mathrm{N}$-independent, $\lambda$ byp, plates on the nus mutant at the restrictive temperature. (2) A phage unable to express $\mathrm{N}$ function, the

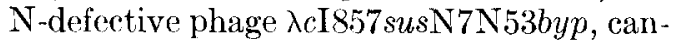
not grow in nus. However, these observations are consistent with the idea that nus affects expression of $\mathrm{N}$ function, if we assume that nus causes lower levels of $\mathrm{N}$ function to be expressed. Experiments with $\lambda$ sex, a phage which cxpresses lower levels of $\mathrm{N}$, in the $n u s^{+}$host indicate that this is the case. In the nus host the expression of $\mathrm{N}$ function by $\lambda$ sex is sharply reduced and the 
phage acts as though it were $\mathrm{N}$-defective. In addition, our studies indicate that nus has varying effects on the regulation of various components of $\lambda$ growth which are under $\mathrm{N}$ control.

Although a formal model explaining nus action has been proposed (Friedman, 1971), it is not presently possible to define the precise mechanism of action of the nus mutation. Clearly, the dominance of the Nus $^{+}$phenotype rules out the possibility that the inhibitory effect is due to the synthesis of a product which inactivates the $\mathrm{N}$ protein. But what still remains to be determined is at what level nus acts; as an inhibitor of $\mathrm{N}$ gene transcription or translation or as an inhibitor of $\mathrm{N}$ protein action. We have therefore discussed nus action in as general a way as possible, as an interference with the expression of $\mathrm{N}$ function without any implication of any specific mechanism.

Functions which map distal to $\mathrm{N}$ in the $\mathrm{N}$-cIII-int operon do not seem to be expressed in the nus bacterium. This was shown by the observation that three genes coded for in this operon, red $\alpha, \delta$, and $\gamma$, are not expressed in nus. Quantitative measurements of the red $\alpha$ gene product, exonuclease, showed that this enzyme is not synthesized at any time during the infection at $42^{\circ}$. This complete turn-off of exonuclease synthesis can be explained in either of two ways. The stimulation of synthesis of exonuclease by $\mathrm{N}$ function might be totally inhibited by nus. Alternatively, nus might delay $\mathrm{N}$ expression for sufficient time to allow a second regulatory function to act. This function is coded for by the tof (or cro) gene. The tof gene product is known to shut off expression of genes in the N-cIII-int operon during the later part of the phage growth cycle (Pero, 1971). Studies in this laboratory are in progress to distinguish between the alternative explanations.

The observation that $\mathrm{N}$ function is expressed under conditions where other functions coded for in the N-cIII-int operon are not, is not surprising. In the absence of $\mathrm{N}$ function only the $\mathrm{N}$ gene of this operon is transcribed (Kumar et al., 1968; Kourilsky et al., 1968). And as would be expected, the site where $\mathrm{N}$ acts to stimulate transcription of the N-cIII-int operon has been mapped to the left of the $\mathrm{N}$ gene, downstream from both $\mathrm{P}_{\mathrm{L}}$ and $\mathrm{N}$ (Franklin, 1971). Therefore, if nus inhibits $\mathrm{N}$ stimulation of the N-cIIIint operon, we would expect it to affect only the expression of functions downstream from the site of action of $\mathrm{N}$ product.

In the case of vegetative functions, the action of the nus mutation on $\mathrm{N}$ stimulation is not clear. Obviously, nus inhibits the expression of sufficient functions to block $\lambda$ phage production at $42^{\circ}$. The fact that the byp mutation relieves part of the block in $\lambda$ growth in nus is taken as strong evidence that $\mathrm{N}$ stimulation of $\mathrm{Q}$ is inhibited by the nus mutation. In addition, the nin mutation which also frees $Q$ synthesis from $\mathrm{N}$ control also permils $\lambda$ to grow on nus at $42^{\circ}$. However, single-step grow th experiments revealed a significant difference between the growth of the two phages in nus compared to their growth in the nus ${ }^{+}$host. The appearance of viable phage following infection with $\lambda$ nin occurs at the same time in the two hosts. The appearance of $\lambda b y p$ delays about 20 min in nus.

The difference in the nature of $\mathrm{N}$-independent growth of $\lambda$ nin and $\lambda b y p$ suggests a reason for their differing growth patterns on K-95. While both the nin and byp mutations free $\mathrm{Q}$ expression from $\mathrm{N}$ control, only nin appears to free expression of functions regulated by $\mathrm{P}_{\mathrm{R}}$ from $\mathrm{N}$ control (Court, 1970). The byp mutation appears only to remove $Q$ synthesis from $\mathrm{N}$ control, suggesting that the effect of nus on $\lambda b y p$ growth must be on $\mathrm{N}$ stimulation of transcription initiating at $P_{R}$. This conclusion is consistent with other studies presented which show a delay in the expression of the cII-O-P operon in nus. We have shown that in nus there is a 20-min lag in the onset of killing when prophage-induced lethality depends on the expression of functions under $P_{R}$ control. Since there is evidence that in the absence of $\mathrm{N}$ function, the nin mutation causes an increased expression of functions under $P_{R}$ control (Court, 1970), it is consistent, then, to explain the difference in the growth of $\lambda b y p$ and $\lambda$ nin in $\mathbf{K}-95$ ds a difference in the expression of functions controlled by that promoter. 
Thus we suggest that the delay in the appearance of viable phage as well as the delay in prophage-induced killing is due to the same cause, an inhibitory action of the nus mutation on the expression of functions under $P_{\mathrm{R}}$ control. The temperature-sensitive step in $\lambda$ growth in $n u s$, wo then conclude, is the $\mathrm{N}$ stimulated turn-on of $\mathrm{Q}$ synthesis. If, as we suspect, $\mathrm{N}$ function in nus is expressed at a reduced level, it would then imply that the observed delay in the appearance of viable phage reflects the time it takes for $\lambda$ to express sufficient $\mathrm{N}$ function to stimulate transcription from $P_{R}$. The additional fact that $\lambda$ sex expresses little or no $\mathrm{N}$ function in nus leads to the conclusion that the nus mutation causes $N$ product to be " $u$ ndersupplied."

\section{ACKNOWLEDGMENTS}

We thank the following for their advice and encouragement: M. Gottesman, S. Gottesman, M. Gutai, D. Jackson, E. Jackson, J. L. Rosner, and M. Shulman. These studies were supported by Grant GB-29595X1 from the National Science Foundation and by funds from The University of Michigan Cancer Research Institute.

\section{REFERENCES}

Appleyard, R. K. (1954). Segregation of new lysogenic types during growth of doubly lysogenic strain derived from Escherichia coli K-12. Genetics 26, 440-452.

Baron, L. S., Penido, E., Ryman, I. R., and Falkow, S. (1970). Behavior of coliphage lambda in hybrids between Escherichia coli and Salmonella. J. Bacteriol. 102, 221-233.

Baron, L. S., Ryman, I. R., Johnson, E. M., and Gemski, P., JR. (1972). Lytic replication of coliphage lambda in Salmonella typhosa hybrids. $J$. Bacteriol. 110, 1022, 1031.

Blat'iner, R., Dihlibegg, J., Boettinger, J., FindT, M., and szybalski, W. (1972). Distance from a promoter mutation to an RNA synthesis startpoint on bacteriophage $\lambda$ DNA. Nature (London) New Biol. 237, 232-236.

Butren, B., and Echols, H. (1970). Regulation of bacteriophage $\lambda$ development by gene $\mathrm{N}$ : Properties of a mutation that bypasses $\mathrm{N}$ control of late protein synthesis. Virology 40, 212-222.

CourT, D. L. (1970). Studies of bacteriophage lambda. Ph.D. thesis, University of Rochester.

Court, D., and Campbeit, A. (1972). Gene regulation in $\mathrm{N}$ mutants of bacteriophage $\lambda . J$. Virol. 9, 938-945.

Cocrt, D., and Saro, K. (1969). Studies on novel transducing variants of lambda: Dispensability of genes $\mathrm{N}$ and Q. Virology $39,348-352$.

Echols, H. (1971). Regulation of lytic development. In "The Bacteriophage Lambda" (A. D. Hershey, ed.), pp. 247-270. Cold Spring Harbor Laboratories, New York.

Fiandt, M., Hradecna, Z., Lozeron, H. A., and SzybaLSkI, W. (1971). Electron micrographic mapping of deletions, insertions, inversions, and homologies in the DNA's of coliphages $\lambda$ and phi 80. In "The Bacteriophage Lambda" (A. D. Hershey, ed.), pp. 329-354. Cold Spring Harbor Laboratories, New York.

Franklin, N. C. (1971). The N operon of lambda: Extent and regulation as observed in fusions to the tryptophan operon of Escherichia coli. In "The Bacteriophage Lambda," (A. D. Hershey, ed.), pp. 621-638. Cold Spring Harbor Laboratories, New York.

Friedman, D. (1971). A bacterial mutant affecting $\lambda$ development. In "The Bacteriophage Lambda" (A. D. Hershey, ed.), pp. 733-738. Cold Spring Harbor Laboratories, New York.

Friedman, D. I., and Yarmolinskx, M. B. (1972). Prevention of the lethality of induced $\lambda$ prophage by an isogenic plasmid. Virology 50, 472-481.

Gsorgopoulos, C. (1971). A bacterial mutation affecting $\mathrm{N}$ function. In "The Bacteriophage Lambda" (A. D. Hershey, ed.), pp. 639-645. Cold Spring Harbor Laboratories, New York.

Got'tesman, M., and Y.armolinsky, M. (1968). Integration-negative mutants of bacteriophage lambda. J. Mol. Biol. 31, 487-505.

Gottesman, M. E. and Weisberg, R. A. (1971). Prophage insertion and excision. In "The Bacteriophage Lambda" (A, D. Hershey, ed.), pp. 113-138. Cold Spring Harbor Iaboratories, New York.

Hopkins, N. (1970). Bypassing a positive regulator: Isolation of a $\lambda$ mitant that does not require $\mathrm{N}$ product to grow. Virology 40, 223-229.

KaIser, I). (1971). Lambda DNA replication. In "The Bacteriophage Lambda" (A. D. Hershey, ed.), pp. 195-210. Cold Spring Harbor Laboratories, New York.

Kourilsky, P., Marcaud, L., Sheldrick, P., Luzzati, D., and Gros, F. (1968). Studies on the messenger RNA of bacteriophage $\lambda$. I. Various species synthesized early after induction of the prophage. Proc. Nat. Acad. Sci. U.S. 61, 10131020.

Kumar, S., Bøvre, K., Guha, A., Hradecna, 'Z., Mahfi, V. M., and Szybalski, W. (1968). Orientation and control of transcription in $E$. coli phage $\lambda$. Nature (London) 221, 823-825.

Ltombrerg, E. M. (1960). Genetic and functional aspects of galactose metabolism in Escherichia coli K-12. Symp. Soc. Gen. Microbiol. 10, 115-131. 
LIE1, M. (1970), $\lambda$ mutants which persist as plasmids. J. Virol. 6, 218-225.

Lindahl, G., Sironi, G., Bialy, H., and Calendar, R. (1970). Bacteriophage $\lambda$ : Abortive infection of bacteria lysogenic for phage $\mathrm{P} 2$. Proc. Nat. Acad. Sci. U.S. 66, 587-593.

Lowry, O. H., Rosemrovgh, N. J., FARr, A. L., and Randall, R. J. (1951). Protein measurement with the Folin phenol reagent. J. Biol. Chem. 193, 265-275.

Manly, K. F., Signer, E. R., and Radding, C. M. (1969). Nonessential functions of bacteriophage $\lambda$. Virology 37, 177-188.

NiJkamp, H. J. J., BфVRe, K., and Szybalskl, W. (1970). Controls of rightward transcription in coliphage $\lambda . J . M o l$. Biol. 54, 599-604.

Ogawa, T., and Tomizawa, J. (1968). Replication of bacteriophage DNA. I. Replication of DNA of lambda phage defective in early functions. J. Mol. Biol. 38, 217-225.

Pereira, da Silva, L. H., Eisen, H. A., and $\mathrm{J}_{\mathrm{ACOB}}, \mathrm{F}$. (1968). Sur la réplication du bactériophage $\lambda$. . C. R. Acad. Sci. 266, 926-928.

Prro, J. (1970). Location of the phage $\lambda$ gene responsible for turning off $\lambda$-exonuclease synthesis. Virology 40, 65-71.

Pironio, M., and Ghysen, A. (1970). A bacterial mutation which affects recognition of the $\mathrm{N}$ gene product of bacteriophage $\lambda$. Mol. Gen. Genet. 108, 374-375.

Radding, C. M. (1966). Regulation of $\lambda$ exonu- clease. I. Properties of $\lambda$ exonuclease purified from lysogens of $\lambda$ t11 and wild type. $J$. Mol. Biol. 18, 235-250.

Ronerts, J. W. (1969). Termination factor for RNA synthesis. Nature (London) 224, 1168-1174.

Shulman, M. J., Hallick, L. M., Echols, H., and Signer, E. R. (1970). Properties of recombination-deficient mutants of bacteriophage lambda. J. Mol. Biol. 52,501-520.

Signer, E. R. (1969). Plasmid formation: A new mode of lysogeny by phage $\lambda$. Nature (London) 223, 158-160.

Signer, E. R. (1971). General recombination. In "The Bacteriophage Lambda" (A. D. Hershey, ed.), pp. 139-174. Cold Spring Harbor Laboratories, New York.

Sussman, R., and JACOB, F. (1962). Sur un système de répression thermosensible chez le bactériophage $\lambda$ d'Escherichia coli. C. R. Acad. Sci. 254, 1517-1519.

Szybalski, W., and Herskowitz, I. (1971). Lambda genetic elements. In "The Bacteriophage Lambda" (A. D. Hershey, ed.), pp. 778-779. Cold Spring Harbor Laboratories, New York.

Zissler, J., Signer, E. R, and Schaffer, F. (1971). The role of recombination in growth of bacteriophage lambda. II. Inhibition of growth by prophage P2. In "The Bacteriophage Lambda" (A. D. Hershey, ed.), pp. 469-487. Cold spring Harbor Laboratories, New York. 